\title{
MetaLab 2.0 enables accurate post-translational modifications profiling in metaproteomics
}

Kai Cheng ${ }^{1}$, Zhibin Ning ${ }^{1}, \mathrm{Xu}_{\text {Zhang }}{ }^{1}$, Leyuan $\mathrm{Li}^{1}$, Bo Liao ${ }^{1}$, Janice Mayne ${ }^{1}$ and Daniel Figeys ${ }^{1,2^{*}}$

*Correspondence: dfigeys@uottawa.ca

${ }^{1}$ Department of Biochemistry, Microbiology and Immunology, Ottawa Institute of Systems Biology and Shanghai Institute of Materia Medica-University of Ottawa Joint Center in Systems and Personalized Pharmacology, Faculty of Medicine, University of Ottawa, Ontario, Canada

${ }^{2}$ Molecular Architecture of Life Program, Canadian Institute for Advanced Research, Toronto, Ontario, Canada. 


\section{Supplementary figures and tables}

\begin{tabular}{|c|c|}
\hline Supplementary figure 1 & Portion of the decoy PSMs in closed search that was recovered in open search \\
\hline Supplementary figure 2 & $\begin{array}{l}\text { Comparison of peptide identifications from open search and conventional closed } \\
\text { search in a Homo_HEK293 dataset }\end{array}$ \\
\hline Supplementary figure 3 & $\begin{array}{l}\text { Comparison of peptide identifications from open search and conventional closed } \\
\text { search in a Mock_micro dataset }\end{array}$ \\
\hline Supplementary figure 4 & Quantitative analysis of a mock microbiome dataset \\
\hline Supplementary figure 5 & $\begin{array}{l}\text { The comparison of the identified (a) peptides and (b) species by closed search } \\
\text { and open search from mouse gut microbiota samples. }\end{array}$ \\
\hline Supplementary figure 6 & $\begin{array}{l}\text { The sequence motif of the potential modification } \Delta \text { Mass }=71.0368 \text { in the } \\
\text { Mouse_gut dataset }\end{array}$ \\
\hline Supplementary figure 7 & $\begin{array}{l}\text { The comparison of peptide identifications from open search and conventional } \\
\text { narrow search in Human_gut dataset }\end{array}$ \\
\hline Supplementary figure 8 & $\begin{array}{l}\text { The PSM counts and intensities of unmodified, oxidation/acetylation and } \\
\text { modified peptides from human and microbial proteins }\end{array}$ \\
\hline Supplementary figure 9 & The PSM count ratio of the identified potential modifications from Human_gut \\
\hline Supplementary figure 10 & The network of HexNAc modified human glycoproteins \\
\hline Supplementary figure 11 & $\begin{array}{l}\text { The significantly changed ( } P<=0.05 \text { by two-sample, two-tailed t-test) GO } \\
\text { biological progresses of HexNAc modified human glycoproteins }\end{array}$ \\
\hline Supplementary figure 12 & The taxon of Hex modified glycopeptides from CO and NO samples \\
\hline Supplementary figure 13 & The functions of the microbial proteins modified by (a) Hex and (b) HexNAc \\
\hline Supplementary figure 14 & The taxon of HexNAc2 modified glycopeptides from $\mathrm{CO}$ and NO samples \\
\hline Supplementary figure 15 & The taxon of Bacillosamine modified glycopeptides from $\mathrm{CO}$ and NO samples \\
\hline Supplementary table 1 & The features used for the machine learning classification \\
\hline Supplementary table 2 & The information of the analyzed benchmark dataset \\
\hline Supplementary table 3 & $\begin{array}{l}\text { The } 40 \text { unknown } \Delta \text { Mass which can be constructed from two known modifications } \\
\text { already identified from this dataset }\end{array}$ \\
\hline Supplementary table 4 & The glycan oxonium ions used for the determination of glycopeptides spectra \\
\hline Supplementary table 5 & The Enriched Biological Process (GO) from the HexNAc modified human proteins \\
\hline Supplementary table 6 & The glycopeptides and their taxons and functions \\
\hline
\end{tabular}




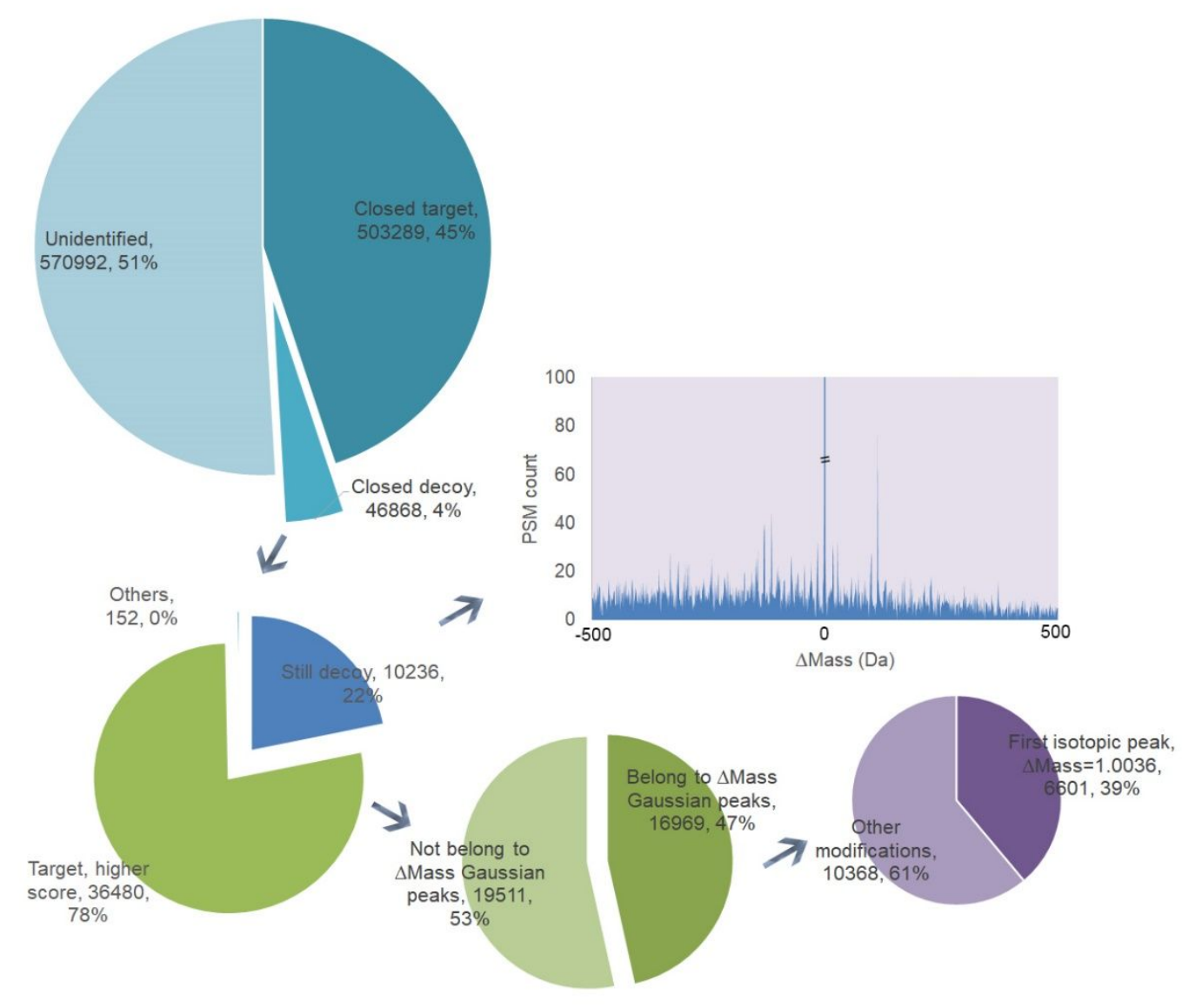

Supplementary Figure 1. Portion of the decoy PSMs in closed search that was recovered in open search. In the closed search 45\% of the MS2 spectra were identified as target PSMs, 4\% were identified as decoys and $51 \%$ of the MS2 spectra were unidentified. It was found that $78 \%$ of the decoy PSMs in closed search were matched to the target sequences and received higher scores in open search. The remaining $22 \%$ were decoy and evenly distributed in the $\triangle$ Mass range, except that the PSMs concentrated on the 0 Da position. For the PSMs that recieved higher scores with target sequences, $47 \%$ belonged to the determined $\Delta$ Mass peaks, which meant this part was recovered by the open search strategy. 


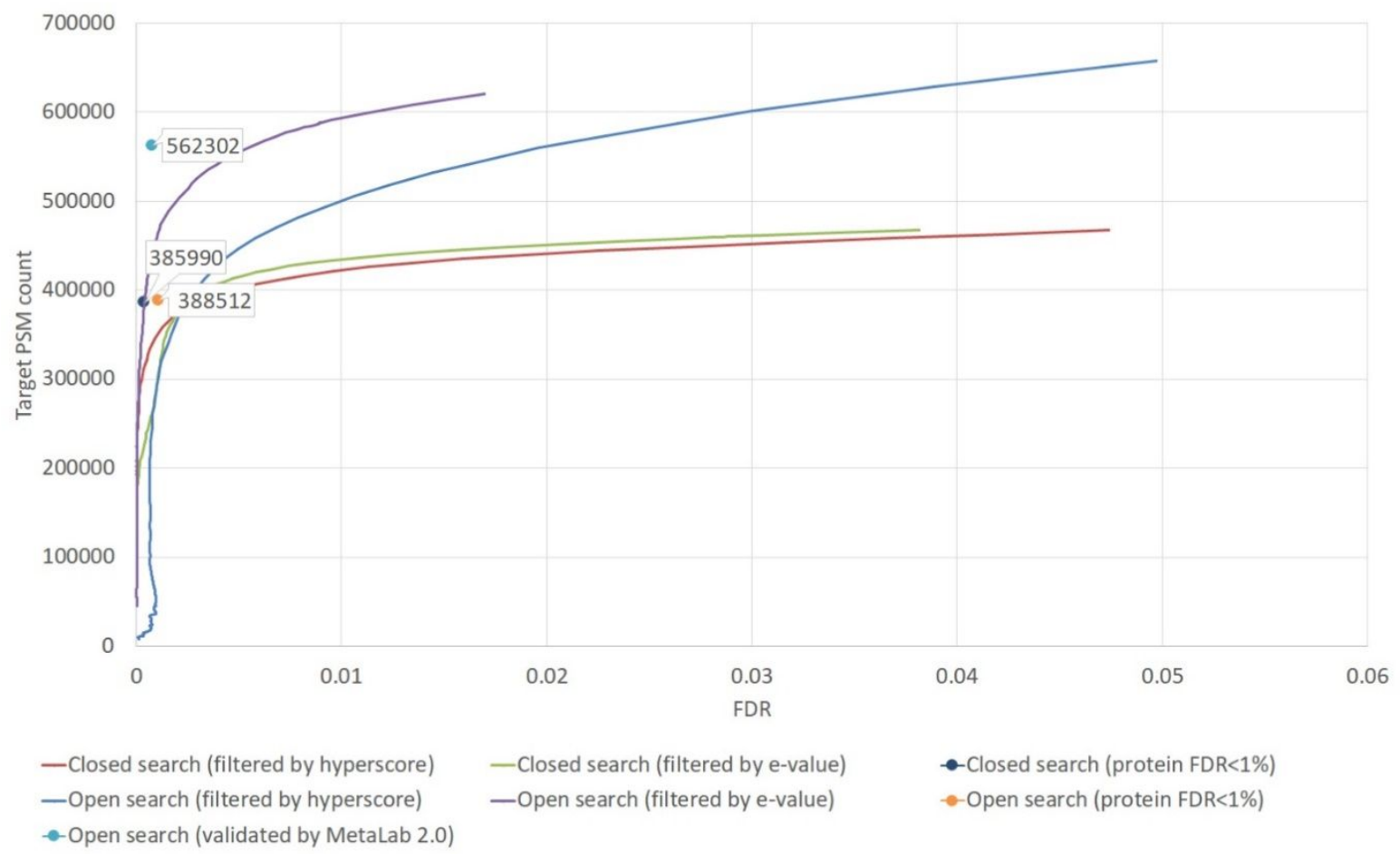

Supplementary Figure 2. Comparison of peptide identifications from open search and conventional closed search in a Homo_HEK293 dataset. The curves were obtained by increasing the score thresholds (hyperscore or e-value) gradually to get the corresponding FDR and target PSM number. The dots were obtained by restricting the FDRs in both of the peptide and protein levels below 0.01 then got the FDR and the target PSM number. In MetaLab 2.0 workflow a developed multistage filtering strategy was utilized. As a comparison, if this method was not used, a protein inference method was applied directly based on the search result to get the scores of proteins and peptides. 


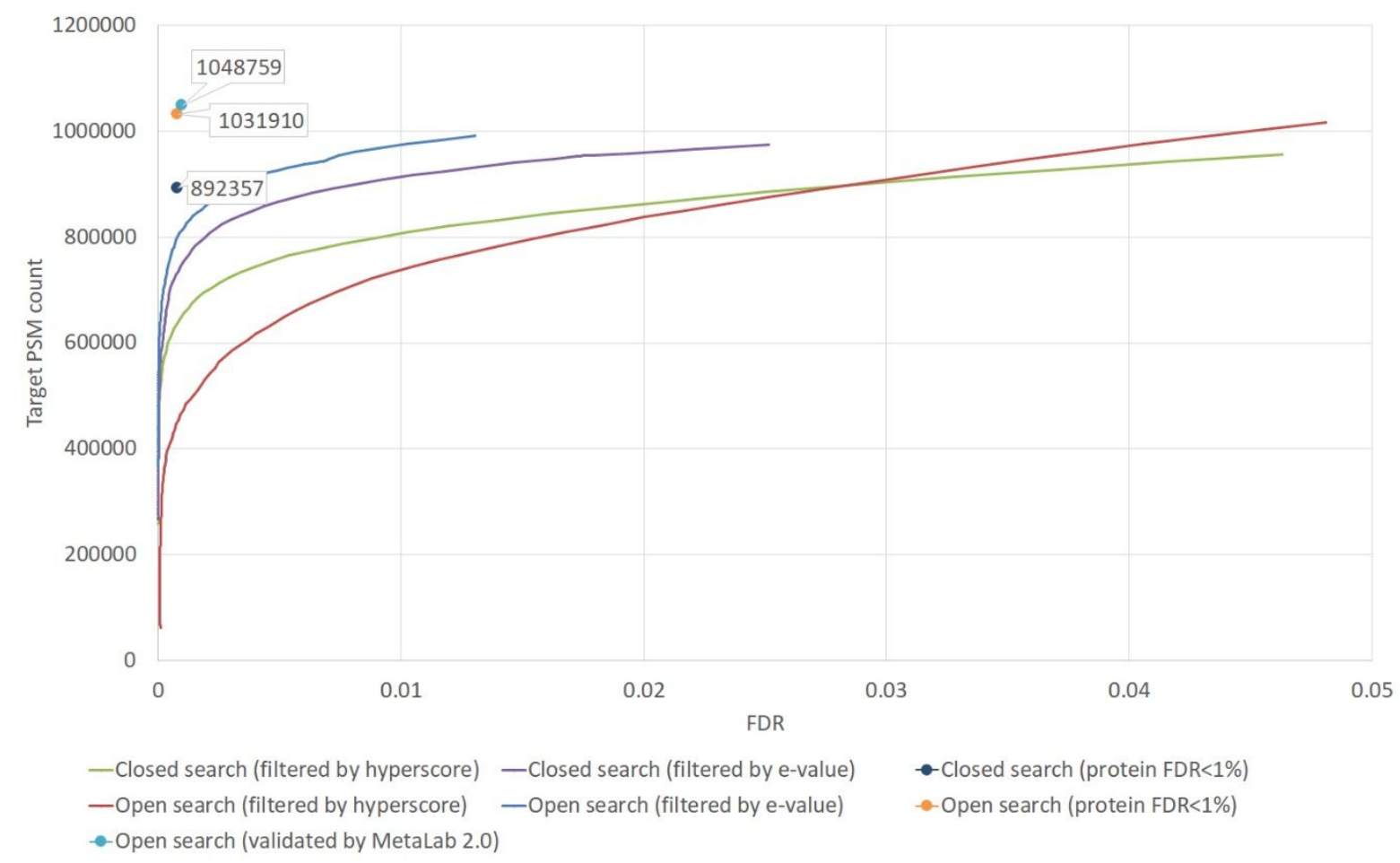

Supplementary Figure 3. Comparison of peptide identifications from open search and conventional closed search in a Mock_micro dataset. The curves were obtained by increasing the score thresholds (hyperscore or e-value) gradually to get the corresponding FDR and target PSM number. The dots were obtained by restricting the FDRs in both of the peptide and protein levels below 0.01 then got the FDR and the target PSM number. In MetaLab 2.0 workflow a developed multistage filtering strategy was utilized. As a comparison, if this method was not used, a protein inference method was applied directly based on the search result to get the scores of proteins and peptides. 


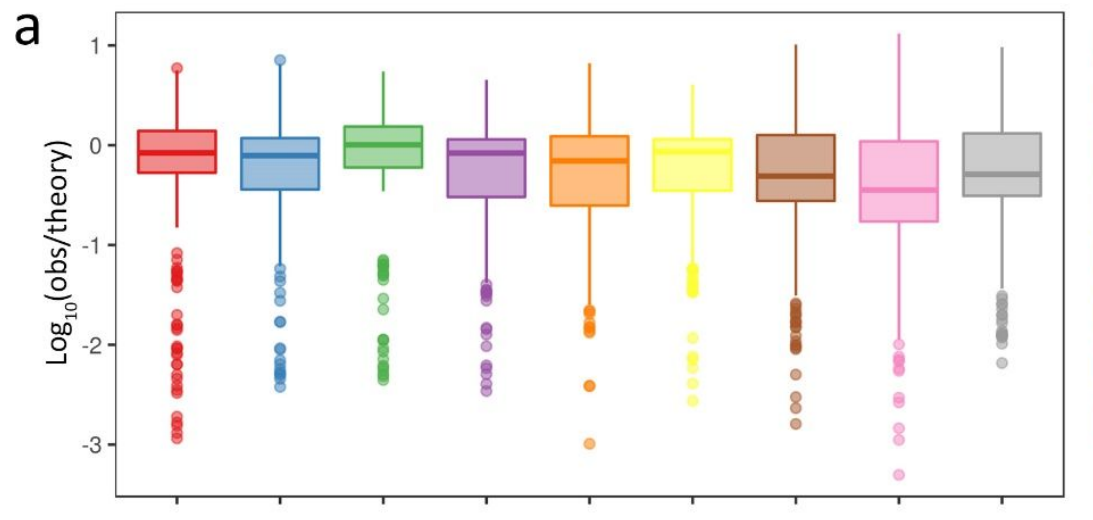

Equal cell number (all)

Equal cell number (modified)

Equal cell number (unmodified)

Equal protein amount (all)

Equal protein amount (modified)

Equal protein amount (unmodified)

$\square_{\square}^{\prime}$ Uneven (all)

Uneven (modified)

Uneven (unmodified)

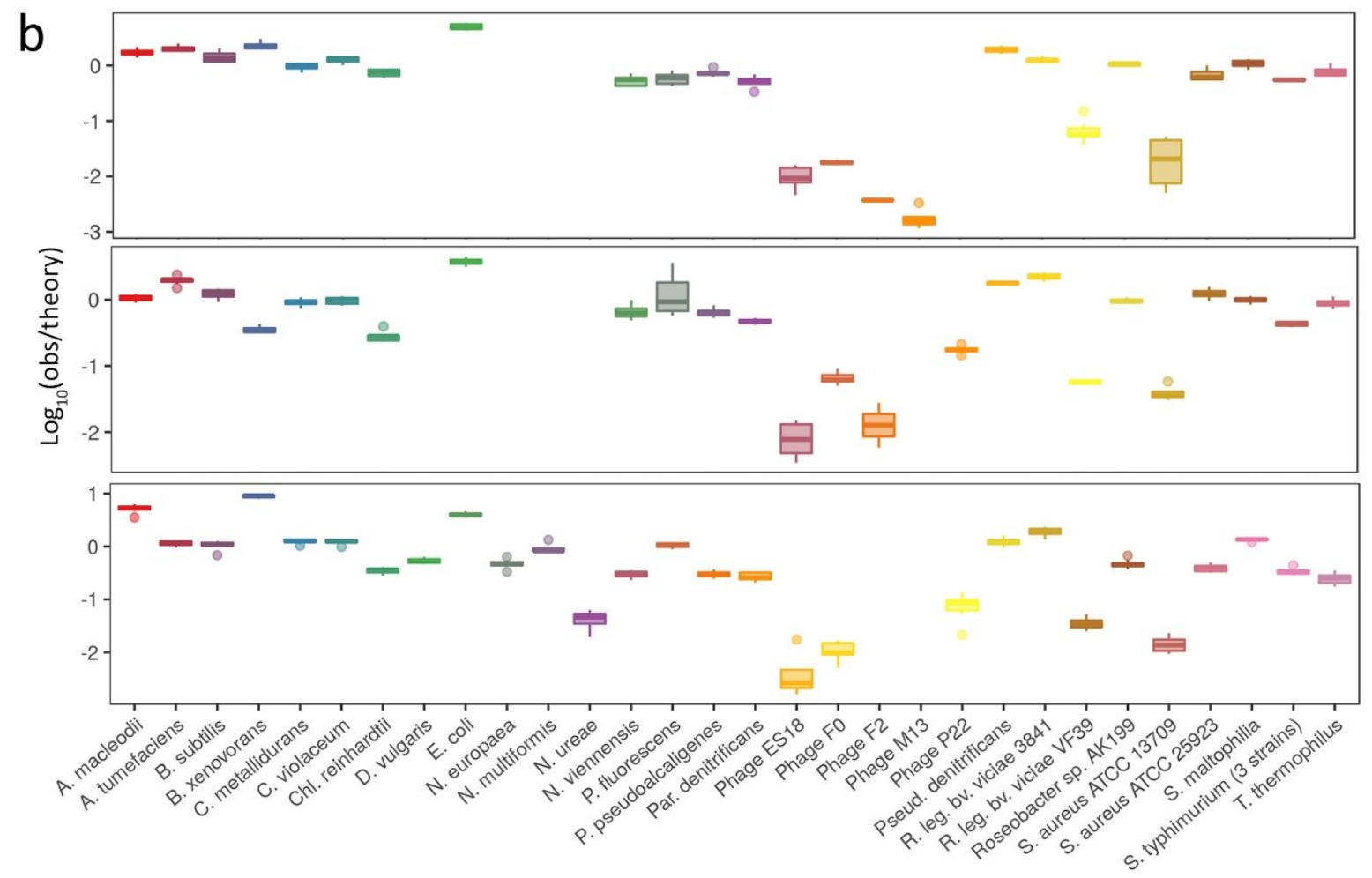

Supplementary Figure 4. Quantitative analysis of a mock microbiome dataset. (a) Deviation between the observed and theoretic relative abundance of species in different samples. The abundance of species were estimated by all the peptides, only unmodified peptides and only modified peptides, respectively. (b) Quantification of the mock communities at the species levels. The bottom and top of the boxes are the first and third quartiles, respectively, the middle lines represent the sample median. 

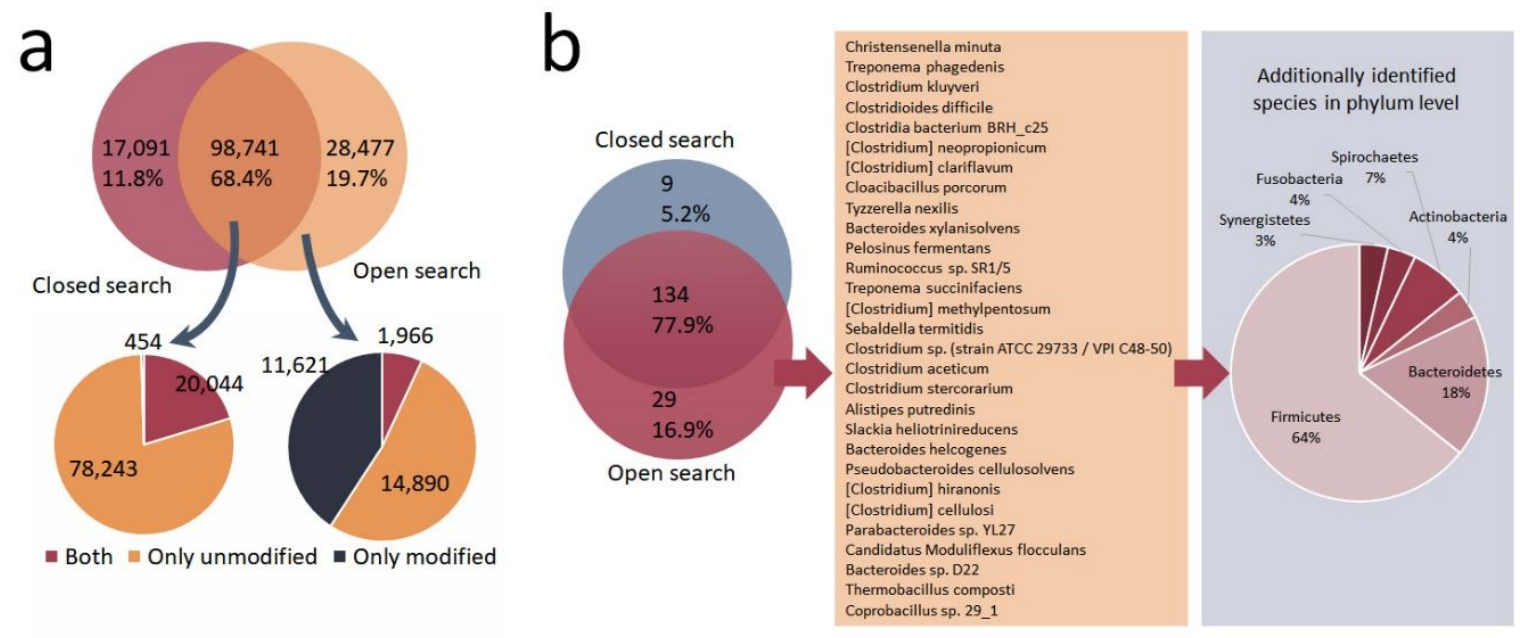

Supplementary Figure 5. The comparison of the identified (a) peptides and (b) species by closed search and open search from mouse gut microbiota samples. 


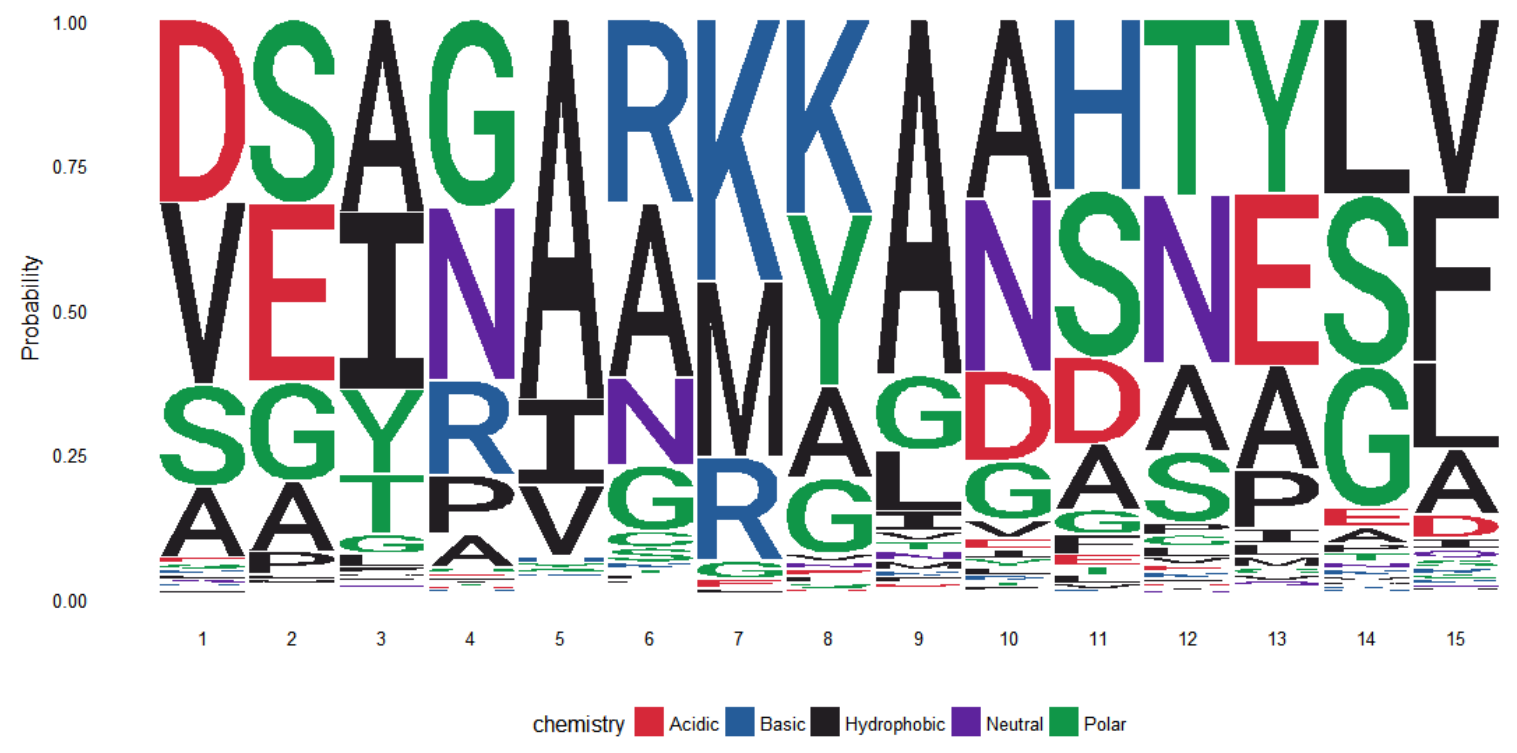

Supplementary Figure 6 . The sequence motif of the potential modification $\Delta$ Mass $=71.0368$ in the Mouse_gut dataset. The length of the sequence window was 7 so the " 8 " in the horizontal axis represents the localization site. 
a
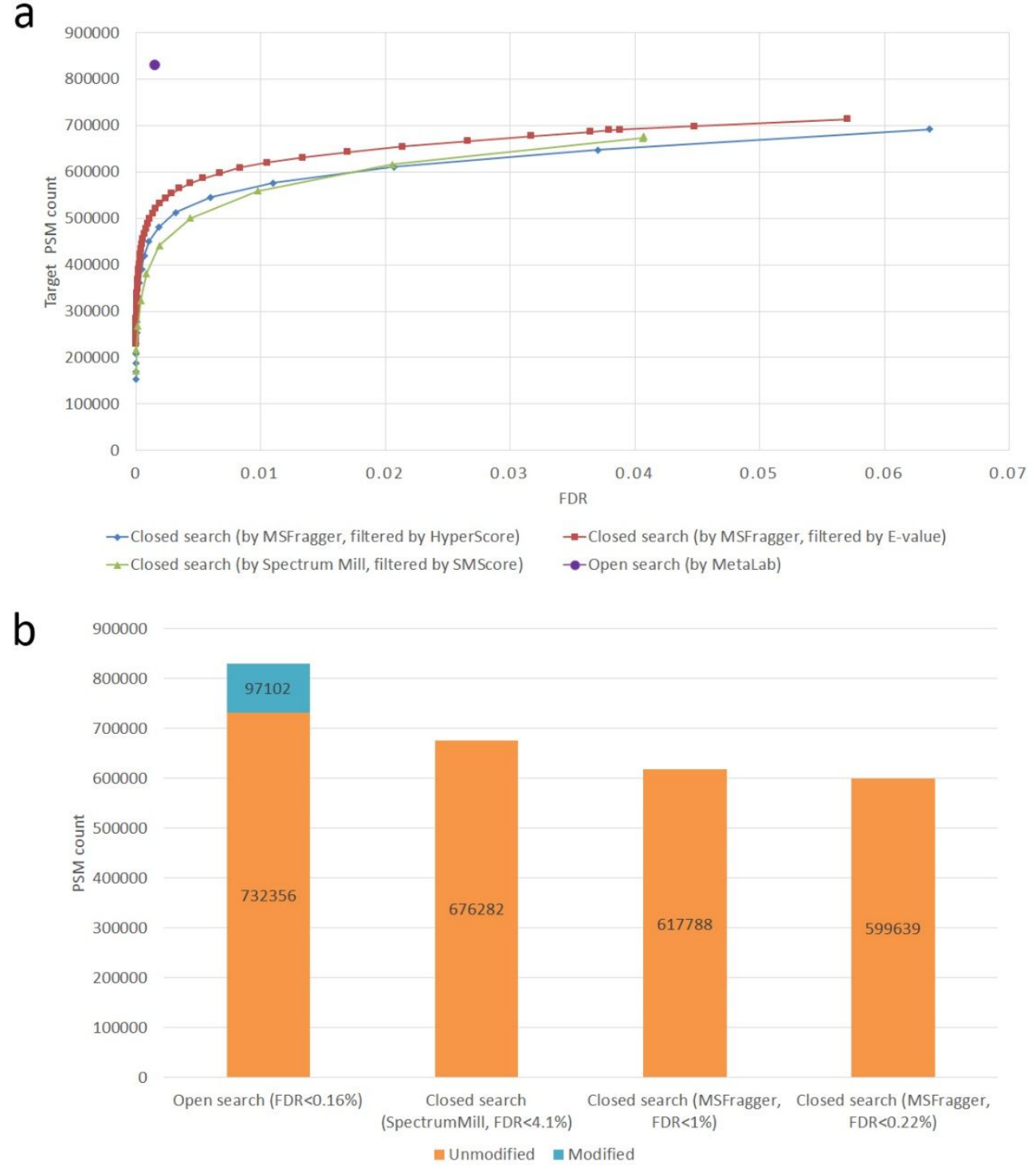

Supplementary Figure 7. The comparison of peptide identifications from open search and conventional narrow search in Human_gut dataset. (a) At the same FDR, far more PSMs were obtained using our strategy. The Spectrum Mill search result was downloaded from https://www.ebi.ac.uk/pride/archive/projects/PXD008870/files;jsessionid=3C8E74D24253F9EABDBE1E88 5B89394C (b) More PSMs were identified by open search, even only considering the unmodified peptides (peptides with oxidation on Met and/or acetylation on protein $n$-term were also included in this part, the modified part represented the peptides with other modifications identified by open search). The second column: the results were downloaded from the above link directly and no filtering was performed. Less PSMs were obtained at a much higher FDR. The third column: filtered PSMs by e-value to restrict the FDR $<0.01$. The fourth column: performed filtering at protein, peptide and PSMs levels simultaneously to keep the FDRs at all of the three levels below 0.01 . 

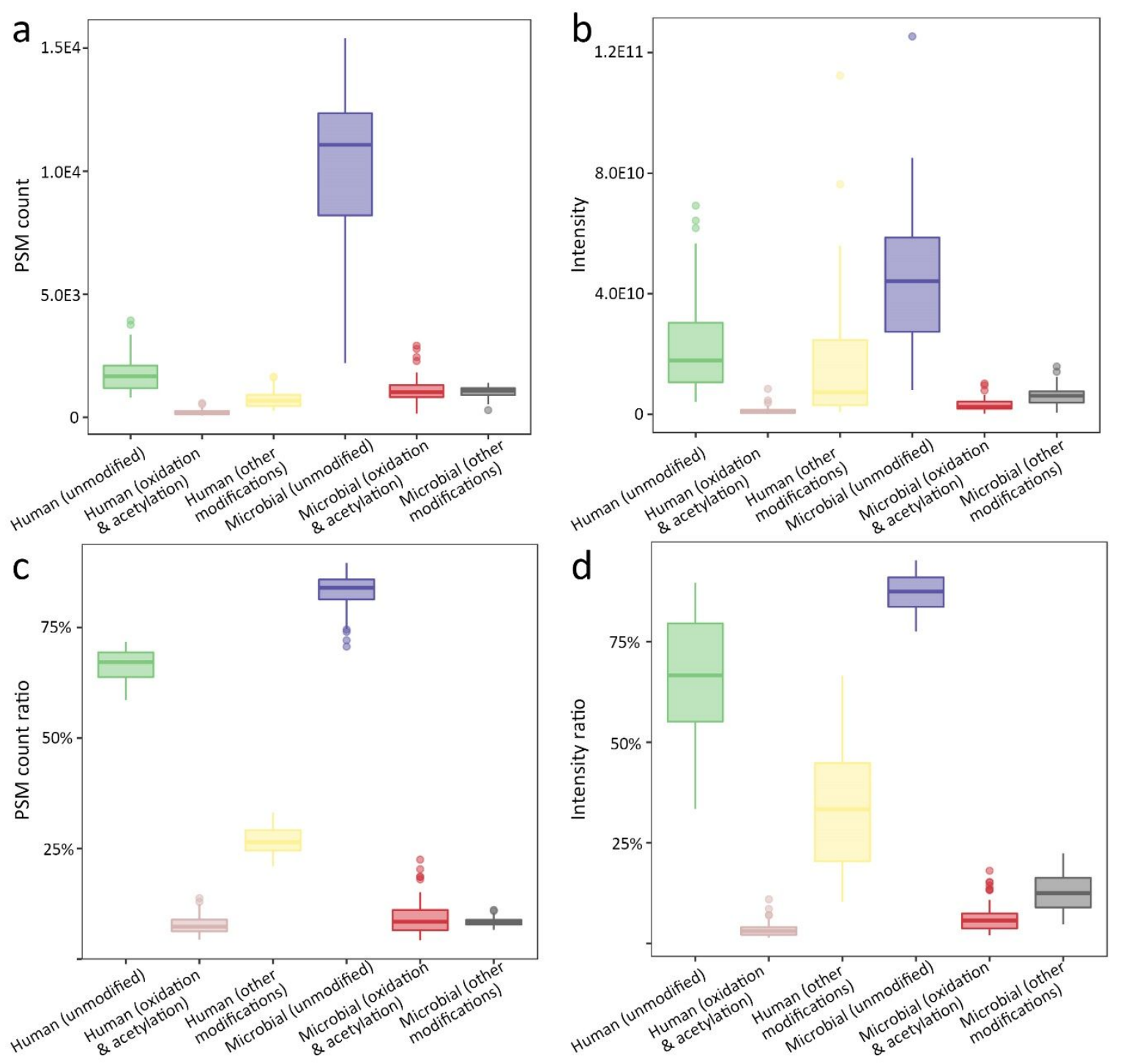

Supplementary Figure 8. The PSM counts and intensities of unmodified, oxidation/acetylation and modified peptides from human and microbial proteins. (a)(b) showed the absolute values of the PSM count and intensity. (c)(d) showed the relative values, i.e., the ratios of unmodified, oxidation/acetylation and modified peptides of the total amount from human and microbial proteins. The bottom and top of the boxes are the first and third quartiles, respectively, the middle lines represent the sample median. 


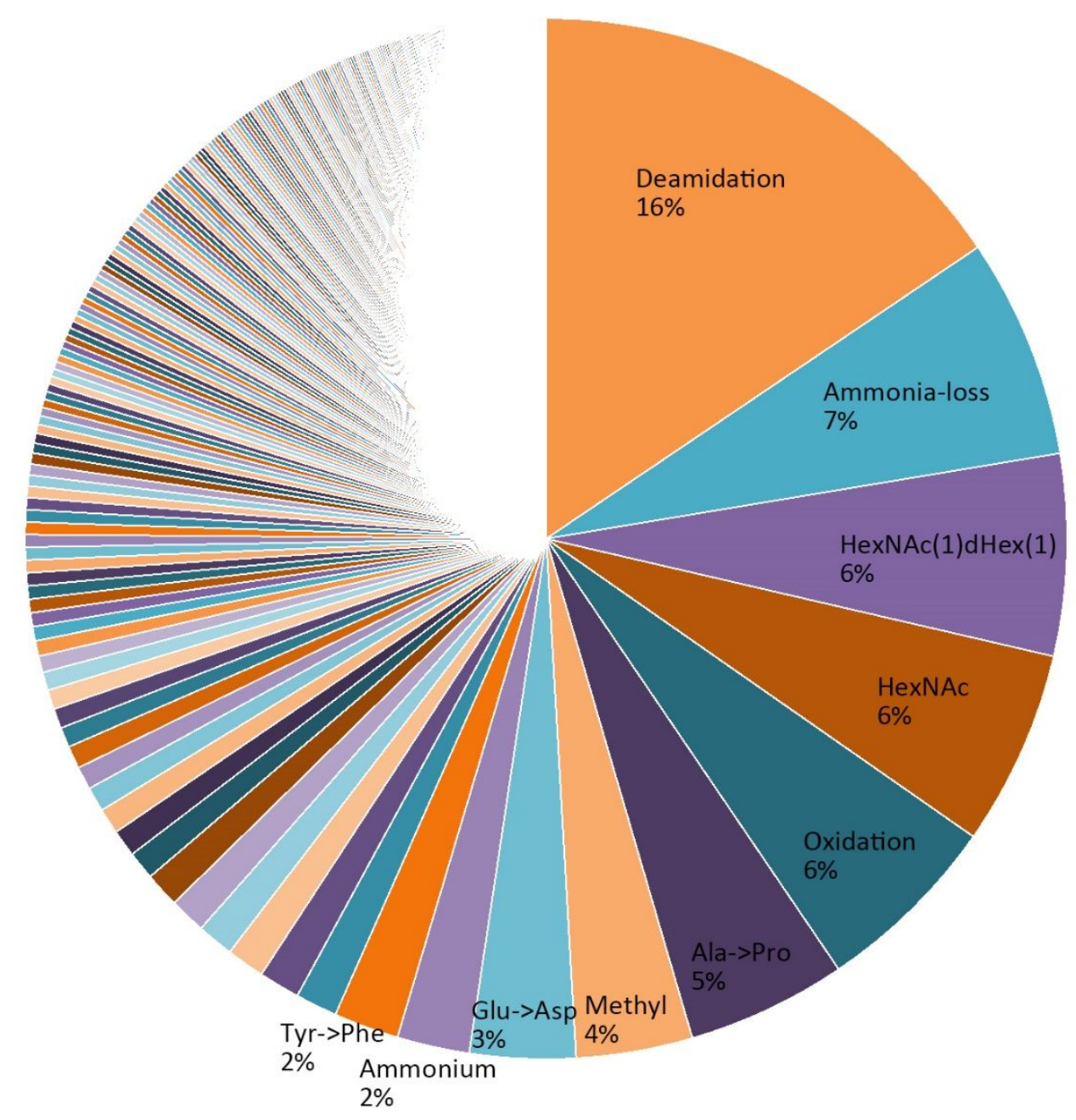

Supplementary Figure 9. The PSM count ratio of the identified potential modifications from Human_gut. 


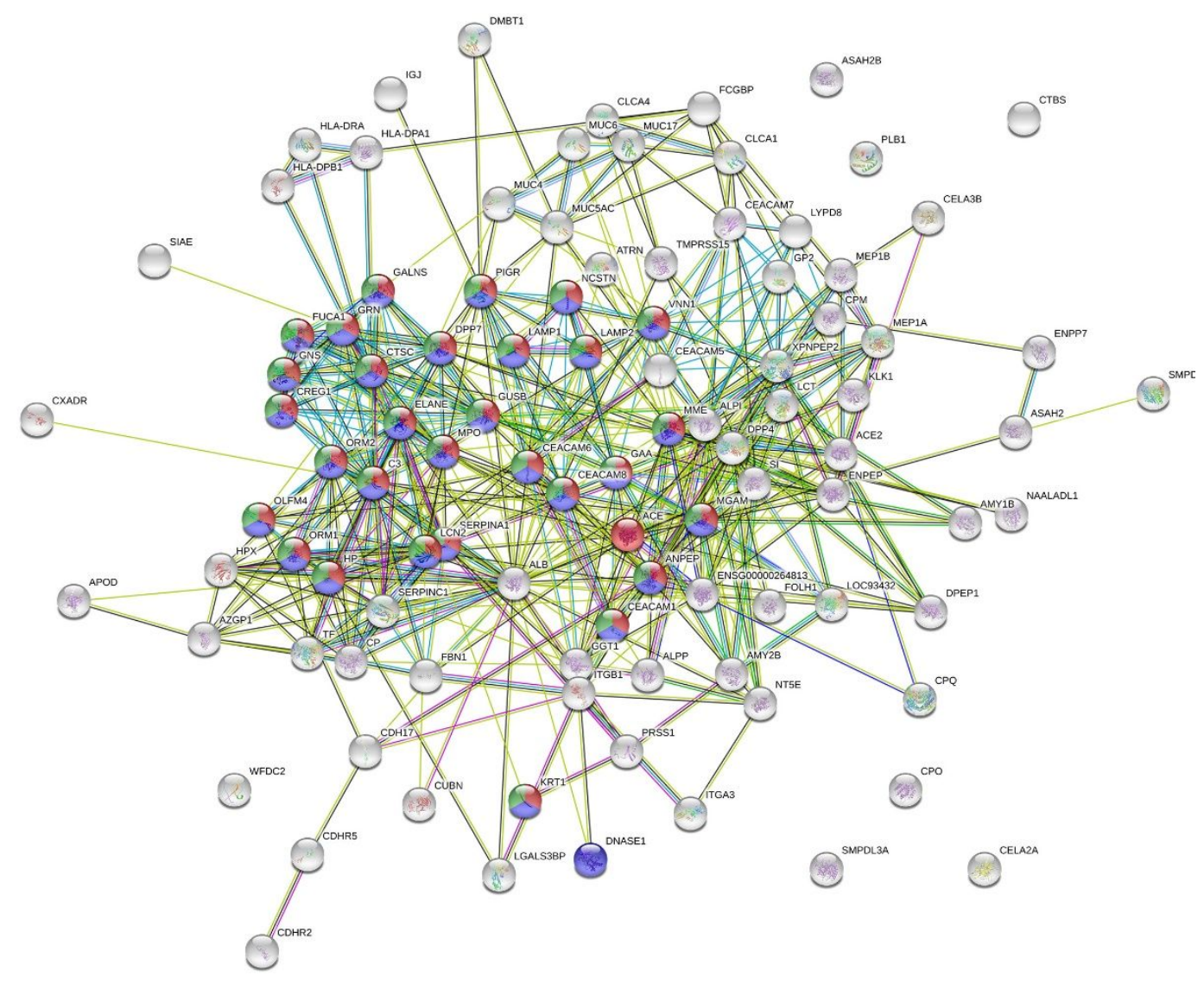

Supplementary Figure 10. The network of HexNAc modified human glycoproteins. Red: neutrophil mediated immunity (GO:0002446); blue: neutrophil activation involved in immune response (GO:0002283); green: neutrophil degranulation (GO:0043312). 

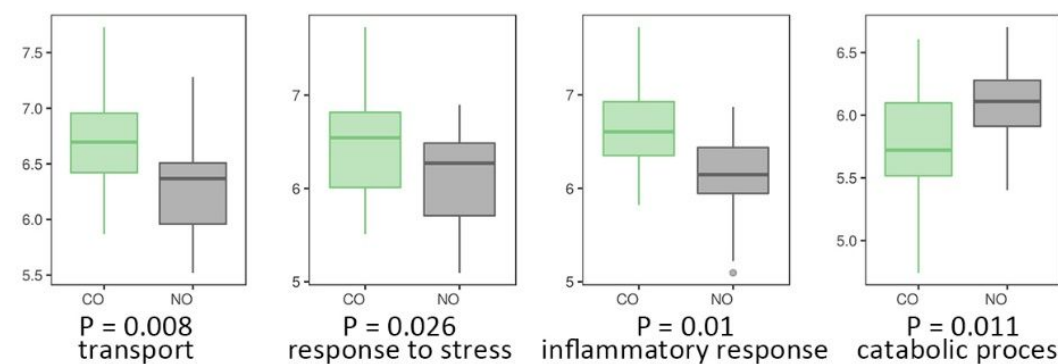

response to stress
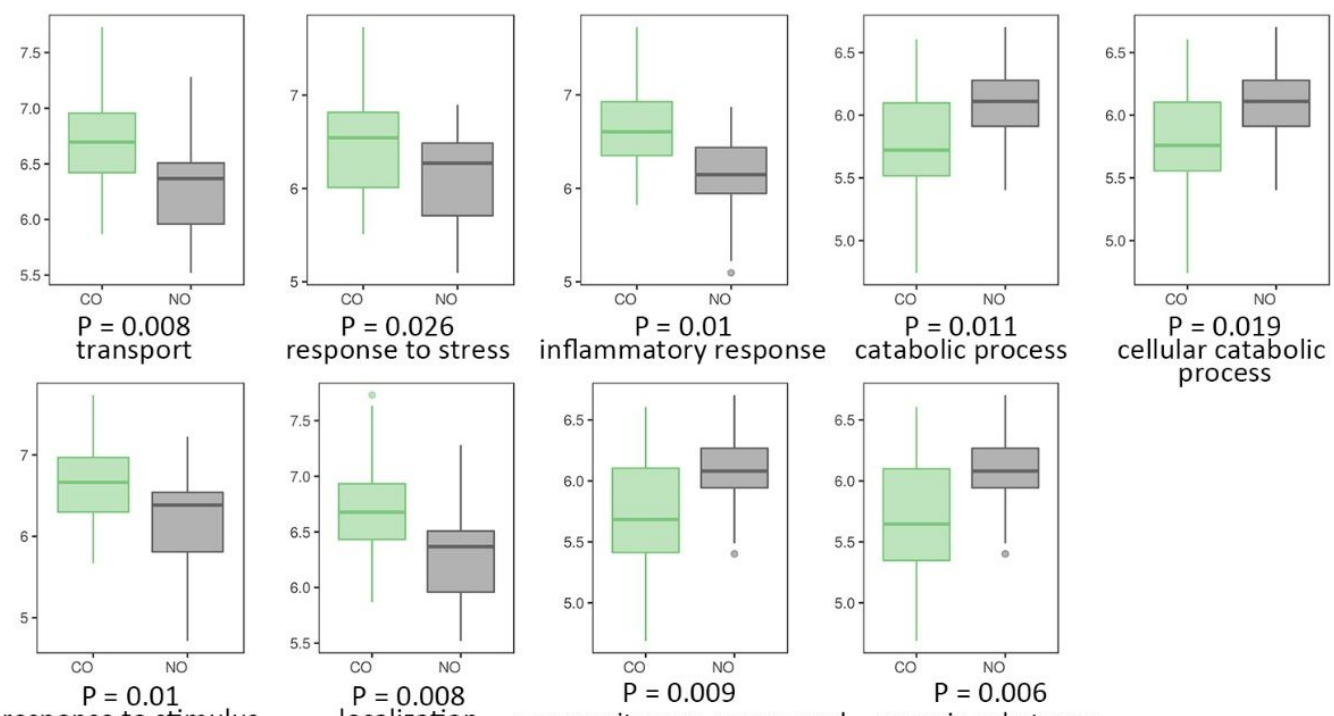

process

response to stimulus

localization

organonitrogen compound catabolic process

organic substance catabolic process

Supplementary Figure 11. The significantly changed ( $P<=0.05$ by two-sample, two-tailed $t$-test) $G 0$ biological progresses of HexNAc modified human glycoproteins. The bottom and top of the boxes are the first and third quartiles, respectively, the middle lines represent the sample median. 
a

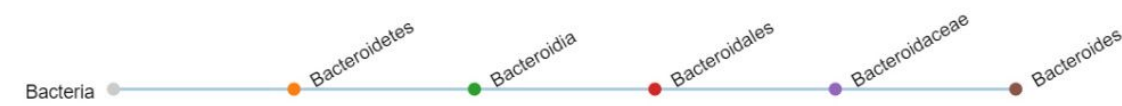

Hex@CO

b

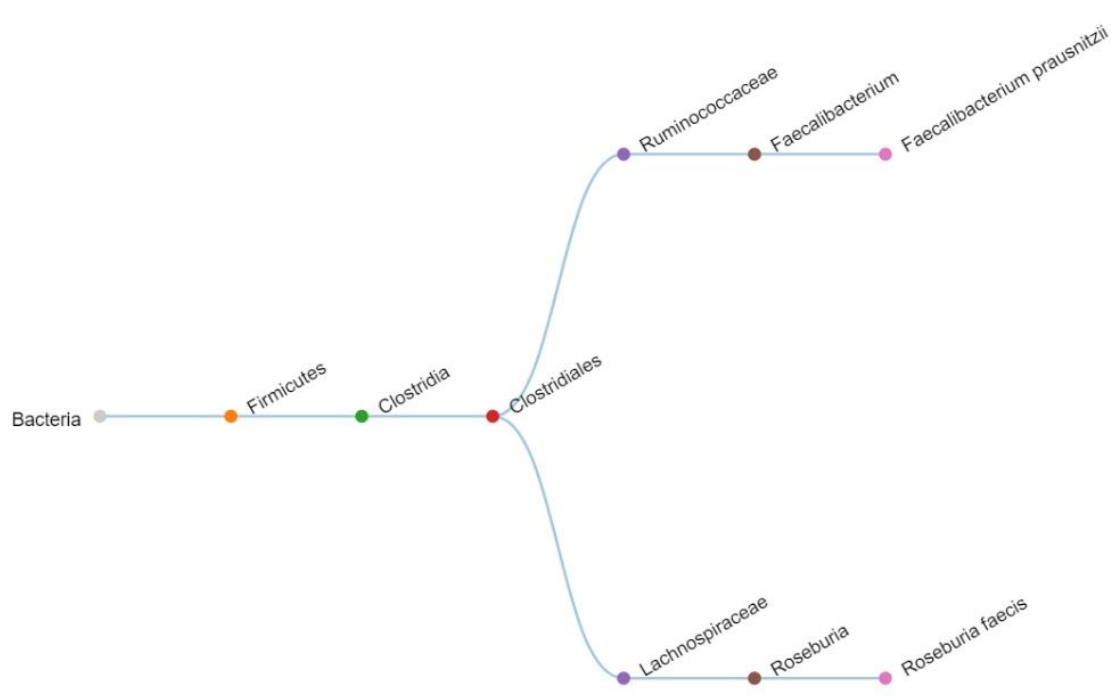

Hex@NO

Supplementary Figure 12. The taxon of Hex modified glycopeptides from $\mathrm{CO}$ and NO samples. 
a

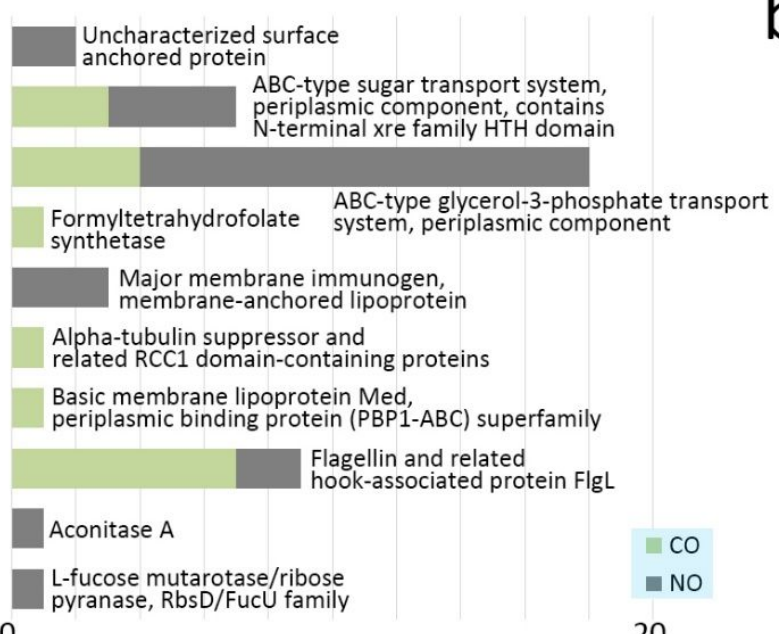

b

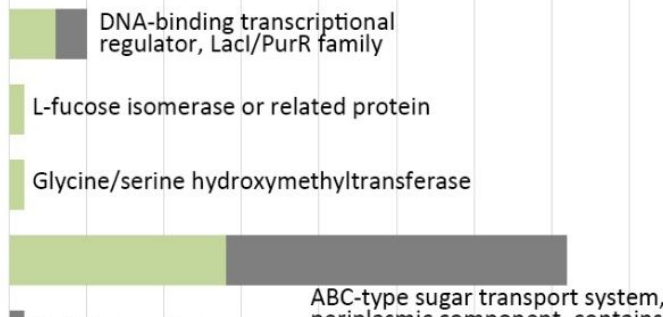

$\begin{array}{ll}\text { ABC-type sugar transport system } \\ \text { cysteine synthase } & \text { periplasmic component, contains }\end{array}$ $\mathrm{N}$-terminal xre family $\mathrm{HTH}$ domain

Molecular chaperone DnaK (HSP70)

Ribosome-associated translation inhibitor RaiA

$A B C$-type glycerol-3-phosphate transport system, periplasmic component

PSM count

Supplementary Figure 13. The functions of the microbial proteins modified by (a) Hex and (b) HexNAc. CO: control subjects; NO; new-onset patients. 
a

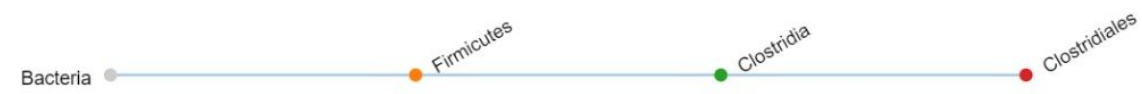

\section{HexNAc2@CO}

b

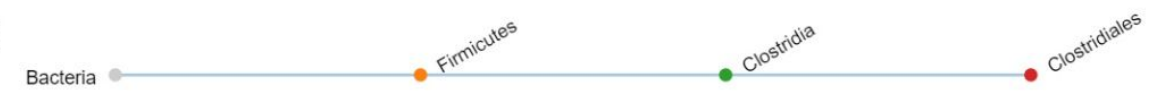

HexNAc2 @NO

Supplementary Figure 14. The taxon of HexNAc2 modified glycopeptides from CO and NO samples. 

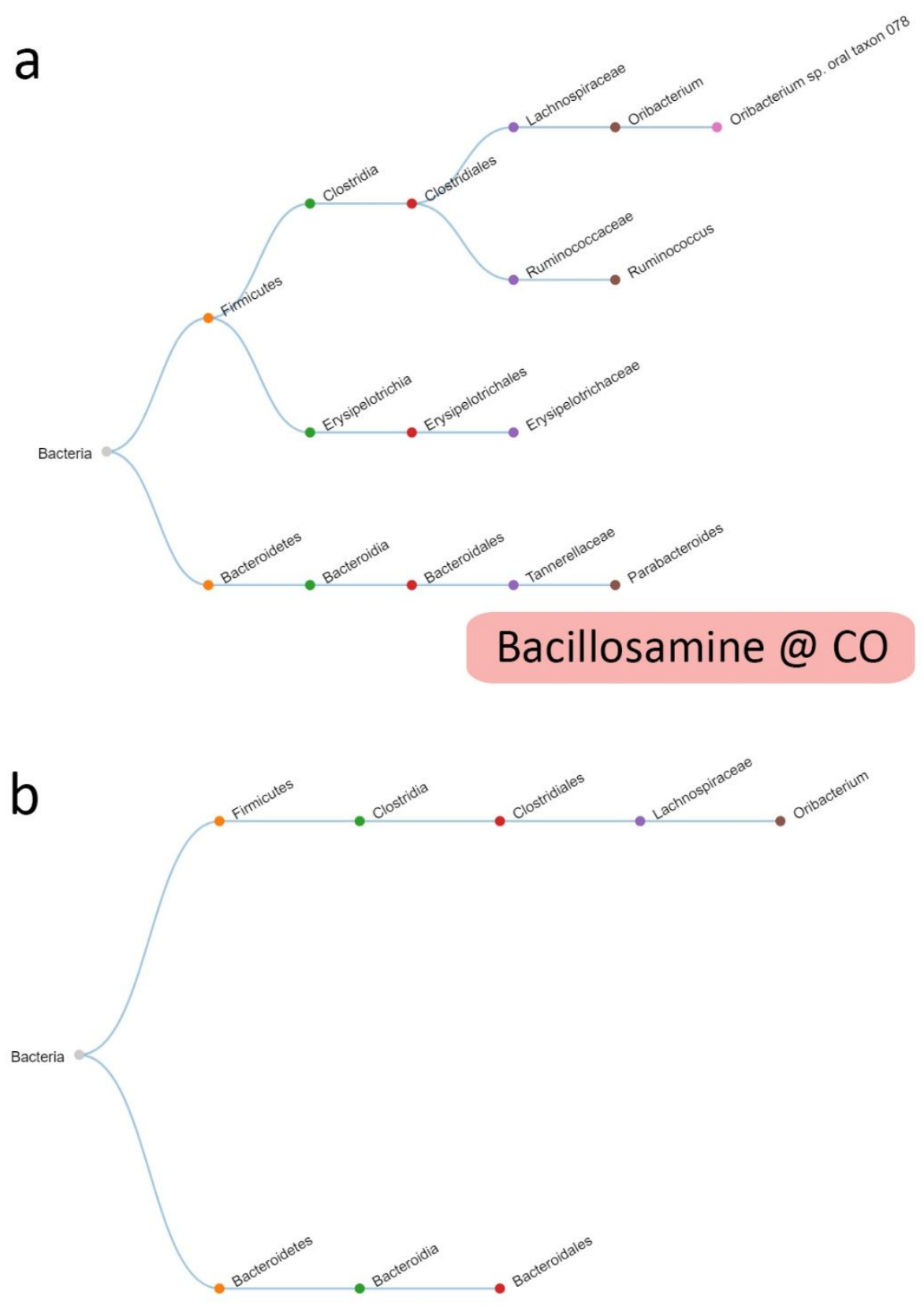

Bacillosamine @NO

Supplementary Figure 15. The taxon of Bacillosamine modified glycopeptides from CO and NO samples. 
Supplementary Table 1. The features used for the machine learning classification.

\begin{tabular}{|c|c|}
\hline Name & Description \\
\hline charge & Charge state of the precursor ion \\
\hline pepMass & The molecular weight of the peptide \\
\hline pepLen & The length of the peptide \\
\hline premr & The mass of the precursor ion \\
\hline massDiff & The mass difference (Da) \\
\hline massDiffPPM & The mass difference (PPM) \\
\hline miss & The number of miss cleavages \\
\hline num_tol_term & The number of tryptic termini \\
\hline tot_num_ions & The number of peptide fragment ions predicted for peptide \\
\hline num_matched_ions & The number of matched ions \\
\hline hyperscore & The hyperscore of the PSM \\
\hline nextscore & The hyperscore of the second ranked match \\
\hline deltascore & The difference between the top hyperscore and second hyperscore \\
\hline _logExpect & $-\log _{10}($ Expect $)$ \\
\hline bintensity & The total intensity of the matched b ions \\
\hline yintensity & The total intensity of the matched $y$ ions \\
\hline brankscore & $\begin{array}{l}\text { The total rank score of the matched b ions (if there are } N \text { peaks in a MS2 spectra, and for one } \\
\text { peak its intensity is higher than } M \text { peaks (max value of } M \text { is } N-1 \text { ), the rank score is calculated } \\
\text { as }(M+1) / N \text { ) }\end{array}$ \\
\hline yrankscore & The total rank score of the matched $y$ ions \\
\hline bcount & The number of matched $b$ ions \\
\hline ycount & The number of matched $y$ ions \\
\hline fragDeltaMass & The average $\Delta$ Mass of matched fragment ions \\
\hline modMass & The experimental mass of the potential modification \\
\hline bmodIntensity & The total intensity of the matched $b$ ions with the modification part \\
\hline ymodlntensity & The total intensity of the matched $y$ ions with the modification part \\
\hline bmodrankscore & The total rank score of the matched $b$ ions with the modification part \\
\hline ymodrankscore & The total rank score of the matched $y$ ions with the modification part \\
\hline fragModDeltaMass & The average $\Delta$ Mass of matched fragment ions with the modification part \\
\hline gaussian_a & The parameter a of the $\Delta$ Mass Gaussian peak $\left(f_{(x)}=a e^{-(x-b)(x-b) / c}\right)$ \\
\hline gaussian_b & The parameter $\mathrm{b}$ of the $\Delta$ Mass Gaussian peak $\left(f_{(x)}=a e^{-(x-b)(x-b) / c}\right)$ \\
\hline gaussian_r2 & The coefficient of the curving fitting $\left(1-\mathrm{SS}_{\text {reg }} / \mathrm{SS}_{\text {tot }}\right)$ \\
\hline sameModCount & The total number of PSMs with the same modification \\
\hline samePepCount & The total number of PSMs with the same sequence \\
\hline sameProCount & The total number of PSMs with the same protein \\
\hline
\end{tabular}


Supplementary Table 2. The $\mathbf{4 0}$ unknown $\Delta$ Mass which can be constructed from two known modifications already identified from this dataset.

\begin{tabular}{|c|c|c|c|c|}
\hline Total mass & Mass 1 & Name 1 & Mass 2 & Name 2 \\
\hline-113.085 & 43.0058 & Ala->Asn substitution & -156.102 & $\begin{array}{l}\text { Loss of arginine due to } \\
\text { transpeptidation }\end{array}$ \\
\hline-85.0898 & 43.0058 & Ala->Asn substitution & -128.096 & $\begin{array}{l}\text { Loss of C-terminal K from Heavy } \\
\text { Chain of MAb }\end{array}$ \\
\hline-85.0898 & -14.0158 & Ala->Gly substitution & -71.0743 & Lys->Gly substitution \\
\hline-145.122 & -17.0259 & Pyro-glu from $Q$ & -128.096 & $\begin{array}{l}\text { Loss of C-terminal K from Heavy } \\
\text { Chain of MAb }\end{array}$ \\
\hline-99.0688 & 57.022 & Addition of Glycine & -156.102 & $\begin{array}{l}\text { Loss of arginine due to } \\
\text { transpeptidation }\end{array}$ \\
\hline-170.106 & -14.0158 & Ala->Gly substitution & -156.102 & $\begin{array}{l}\text { Loss of arginine due to } \\
\text { transpeptidation }\end{array}$ \\
\hline 171.1008 & 43.0058 & Ala->Asn substitution & 128.0951 & $\begin{array}{l}\text { Addition of lysine due to } \\
\text { transpeptidation }\end{array}$ \\
\hline 241.1791 & 128.0951 & $\begin{array}{l}\text { Addition of lysine due to } \\
\text { transpeptidation }\end{array}$ & 113.0833 & Acetylhypusine \\
\hline-146.105 & -128.096 & $\begin{array}{l}\text { Loss of C-terminal } K \text { from Heavy } \\
\text { Chain of MAb }\end{array}$ & -18.0106 & Dehydration \\
\hline 355.9057 & 301.9881 & $\begin{array}{l}\text { Unidentified modification of } \\
301.9864 \text { found in open search }\end{array}$ & 53.9191 & Replacement of 2 protons by iron \\
\hline-199.133 & -128.096 & $\begin{array}{l}\text { Loss of C-terminal K from Heavy } \\
\text { Chain of MAb }\end{array}$ & -71.0375 & Gln->Gly substitution \\
\hline-128.059 & -71.0375 & Gln->Gly substitution & -57.0221 & Gln->Ala substitution \\
\hline-128.059 & 28.0317 & di-Methylation & -156.102 & $\begin{array}{l}\text { Loss of arginine due to } \\
\text { transpeptidation }\end{array}$ \\
\hline-87.0327 & -71.0375 & Gln->Gly substitution & -15.9946 & Tyr->Phe substitution \\
\hline-87.0327 & -57.0221 & Gln->Ala substitution & -30.0113 & Thr->Ala substitution \\
\hline-114.044 & -57.0221 & Gln->Ala substitution & -57.0221 & Gln->Ala substitution \\
\hline 311.1296 & 183.0357 & Aminoethylbenzenesulfonylation & 128.0951 & $\begin{array}{l}\text { Addition of lysine due to } \\
\text { transpeptidation }\end{array}$ \\
\hline-112.101 & 15.9953 & Phe->Tyr substitution & -128.096 & $\begin{array}{l}\text { Loss of C-terminal K from Heavy } \\
\text { Chain of MAb }\end{array}$ \\
\hline-112.101 & 43.9908 & Ala->Asp substitution & -156.102 & $\begin{array}{l}\text { Loss of arginine due to } \\
\text { transpeptidation }\end{array}$ \\
\hline 199.1075 & 43.0058 & Ala->Asn substitution & 156.1014 & $\begin{array}{l}\text { Addition of arginine due to } \\
\text { transpeptidation }\end{array}$ \\
\hline 199.1075 & 113.0833 & Acetylhypusine & 86.0383 & 2-hydroxyisobutyrylation \\
\hline-96.1053 & 31.9903 & Pro->Glu substitution & -128.096 & $\begin{array}{l}\text { Loss of C-terminal K from Heavy } \\
\text { Chain of MAb }\end{array}$ \\
\hline 242.1378 & 156.1014 & $\begin{array}{l}\text { Addition of arginine due to } \\
\text { transpeptidation }\end{array}$ & 86.0383 & 2-hydroxyisobutyrylation \\
\hline-101.049 & -71.0375 & Gln->Gly substitution & -30.0113 & Thr->Ala substitution \\
\hline 269.1851 & 156.1014 & $\begin{array}{l}\text { Addition of arginine due to } \\
\text { transpeptidation }\end{array}$ & 113.0833 & Acetylhypusine \\
\hline-227.164 & -156.102 & $\begin{array}{l}\text { Loss of arginine due to } \\
\text { transpeptidation }\end{array}$ & -71.0743 & Lys->Gly substitution \\
\hline-74.1762 & 53.9191 & Replacement of 2 protons by iron & -128.096 & $\begin{array}{l}\text { Loss of C-terminal K from Heavy } \\
\text { Chain of MAb }\end{array}$ \\
\hline 284.1968 & 128.0951 & $\begin{array}{l}\text { Addition of lysine due to } \\
\text { transpeptidation }\end{array}$ & 156.1014 & $\begin{array}{l}\text { Addition of arginine due to } \\
\text { transpeptidation }\end{array}$ \\
\hline 69.9146 & 53.9191 & Replacement of 2 protons by iron & 15.9953 & Phe->Tyr substitution \\
\hline-227.127 & -71.0375 & Gln->Gly substitution & -156.102 & $\begin{array}{l}\text { Loss of arginine due to } \\
\text { transpeptidation }\end{array}$ \\
\hline-204.09 & -156.102 & $\begin{array}{l}\text { Loss of arginine due to } \\
\text { transpeptidation }\end{array}$ & -48.0043 & $\begin{array}{l}\text { Prompt loss of side chain from } \\
\text { oxidised Met }\end{array}$ \\
\hline-186.101 & -156.102 & $\begin{array}{l}\text { Loss of arginine due to } \\
\text { transpeptidation }\end{array}$ & -30.0113 & Thr->Ala substitution \\
\hline
\end{tabular}




\begin{tabular}{lllll}
\hline-172.085 & -15.9946 & Tyr->Phe substitution & -156.102 & $\begin{array}{l}\text { Loss of arginine due to } \\
\text { transpeptidation }\end{array}$ \\
\hline-100.101 & 27.9954 & Formylation & -128.096 & $\begin{array}{l}\text { Loss of C-terminal K from Heavy } \\
\text { Chain of MAb }\end{array}$ \\
\hline-100.101 & -71.0743 & Lys->Gly substitution & -29.028 & Lys->Val substitution \\
\hline 212.1645 & 113.0833 & Acetylhypusine & 99.0671 & N-isopropylcarboxamidomethyl \\
\hline-312.216 & -156.102 & $\begin{array}{l}\text { Loss of arginine due to } \\
\text { transpeptidation }\end{array}$ & -156.102 & $\begin{array}{l}\text { Loss of arginine due to } \\
\text { transpeptidation }\end{array}$ \\
\hline 256.191 & 128.0951 & $\begin{array}{l}\text { Addition of lysine due to } \\
\text { transpeptidation }\end{array}$ & 128.0951 & $\begin{array}{l}\text { Addition of lysine due to } \\
\text { transpeptidation }\end{array}$ \\
\hline 39.9035 & 53.9191 & Replacement of 2 protons by iron & -14.0158 & Ala->Gly substitution \\
\hline 181.0395 & -15.9946 & Tyr->Phe substitution & 197.0491 & glycerylphosphorylethanolamine \\
\hline-144.055 & -156.102 & $\begin{array}{l}\text { Loss of arginine due to } \\
\text { transpeptidation }\end{array}$ & 12.0376 & Thr->Leu/lle substitution \\
\hline 215.1274 & 203.0814 & N-Acetylhexosamine & 12.0376 & Thr->Leu/lle substitution \\
\hline 147.0344 & 31.9903 & Pro->Glu substitution & 115.0265 & $\begin{array}{l}\text { Cleavage product of EGS protein } \\
\text { crosslinks by hydroylamine } \\
\text { treatment }\end{array}$ \\
\hline 312.2021 & 156.1014 & $\begin{array}{l}\text { Addition of arginine due to } \\
\text { transpeptidation }\end{array}$ & 156.1014 & $\begin{array}{l}\text { Addition of arginine due to } \\
\text { transpeptidation }\end{array}$ \\
\hline 36.893 & -17.0259 & Pyro-glu from Q & Replacement of 2 protons by iron \\
\hline-213.112 & -57.0221 & Gln->Ala substitution & -156.102 & $\begin{array}{l}\text { Loss of arginine due to } \\
\text { transpeptidation }\end{array}$ \\
\hline
\end{tabular}


Supplementary Table 3. The glycan oxonium ions used for the determination of glycopeptides spectra.

\begin{tabular}{lllll}
\hline Name & Composition & MW & Glycan oxonium ion 1 & Glycan oxonium ion 2 \\
\hline HexNAc & $\mathrm{C}_{8} \mathrm{O}_{5} \mathrm{NH}_{13}$ & 203.0794 & 204.0867 & 186.0761 \\
\hline HexNAc1dHex1 & $\mathrm{C}_{14} \mathrm{O}_{9} \mathrm{NH}_{23}$ & 349.1373 & 350.1444 & 332.1338 \\
\hline HexNAc2 & $\mathrm{C}_{16} \mathrm{O}_{10} \mathrm{~N}_{2} \mathrm{H}_{26}$ & 406.1588 & 204.0867 & 186.0761 \\
\hline bacillosamine & $\mathrm{C}_{10} \mathrm{O}_{4} \mathrm{~N}_{2} \mathrm{H}_{16}$ & 228.1110 & 229.1183 & 211.1077 \\
\hline
\end{tabular}


Supplementary Table 4. The information of the analyzed benchmark dataset.

\begin{tabular}{|c|c|c|c|c|c|c|}
\hline Dataset ID & $\begin{array}{l}\text { Supplementary } \\
\text { Data ID }\end{array}$ & PRIDE id & Species & Tissues/Cell & $\begin{array}{l}\text { Enrichment } \\
\text { information }\end{array}$ & $\begin{array}{l}\text { Raw file } \\
\text { count }\end{array}$ \\
\hline Homo_HEK293 ${ }^{1}$ & 1 & PXD001468 & Homo sapiens & HEK293 & - & 32 \\
\hline Ecoli_phos ${ }^{2}$ & 2 & PXD008289 & $\begin{array}{l}\text { Escherichia } \\
\text { coli }\end{array}$ & - & Phosphorylation & 9 \\
\hline Mouse_phos ${ }^{3}$ & 3 & PXD001792 & Mus musculus & Kidney & Phosphorylation & 6 \\
\hline Hela_phos ${ }^{4}$ & 4 & PXD004940 & Homo sapiens & HeLa & Phosphorylation & 6 \\
\hline U87_phos 5 & 5 & PXD009227 & Homo sapiens & $\begin{array}{l}\text { U-87 } \\
\text { glioblastoma } \\
\text { cells }\end{array}$ & Phosphorylation & 24 \\
\hline Mock_micro ${ }^{6}$ & 6 & PXD006118 & $\begin{array}{l}\text { Mock } \\
\text { microbiome }\end{array}$ & - & - & 24 \\
\hline Mouse_gut ${ }^{7}$ & 7 & PXD003527 & $\begin{array}{l}\text { Mouse gut } \\
\text { microbial } \\
\text { community }\end{array}$ & - & - & 32 \\
\hline Human_gut ${ }^{8}$ & 8 & PXD008870 & $\begin{array}{l}\text { Human gut } \\
\text { microbial } \\
\text { community }\end{array}$ & - & - & 55 \\
\hline
\end{tabular}


Supplementary Table 5. The enriched Biological Process (GO) from the HexNAc modified human proteins.

\begin{tabular}{|c|c|c|c|c|}
\hline \#term ID & term description & $\begin{array}{l}\text { observed } \\
\text { gene } \\
\text { count }\end{array}$ & $\begin{array}{l}\text { background } \\
\text { gene count }\end{array}$ & $\begin{array}{l}\text { false } \\
\text { discovery } \\
\text { rate }\end{array}$ \\
\hline GO:0002283 & neutrophil activation involved in immune response & 32 & 489 & $5.96 \mathrm{E}-22$ \\
\hline GO:0002446 & neutrophil mediated immunity & 32 & 498 & $5.96 \mathrm{E}-22$ \\
\hline GO:0043312 & neutrophil degranulation & 31 & 485 & $1.06 \mathrm{E}-21$ \\
\hline GO:0002366 & leukocyte activation involved in immune response & 33 & 616 & 4.09E-21 \\
\hline GO:0045055 & regulated exocytosis & 34 & 691 & $7.65 \mathrm{E}-21$ \\
\hline GO:0045321 & leukocyte activation & 36 & 894 & $1.61 \mathrm{E}-19$ \\
\hline GO:0002252 & immune effector process & 36 & 927 & $4.48 \mathrm{E}-19$ \\
\hline GO:0046903 & secretion & 36 & 1070 & $3.77 \mathrm{E}-17$ \\
\hline GO:0002376 & immune system process & 50 & 2370 & $9.78 \mathrm{E}-17$ \\
\hline GO:0006955 & immune response & 40 & 1560 & $2.04 \mathrm{E}-15$ \\
\hline GO:0016192 & vesicle-mediated transport & 40 & 1699 & $3.45 \mathrm{E}-14$ \\
\hline GO:0006508 & proteolysis & 34 & 1203 & $6.35 \mathrm{E}-14$ \\
\hline GO:0050435 & amyloid-beta metabolic process & 7 & 16 & $2.13 \mathrm{E}-09$ \\
\hline GO:0035333 & Notch receptor processing, ligand-dependent & 6 & 7 & $2.93 \mathrm{E}-09$ \\
\hline GO:0016485 & protein processing & 12 & 142 & $3.21 \mathrm{E}-09$ \\
\hline GO:1901564 & organonitrogen compound metabolic process & 61 & 5281 & $3.25 \mathrm{E}-09$ \\
\hline GO:0006810 & transport & 52 & 4130 & $1.42 \mathrm{E}-08$ \\
\hline GO:0002682 & regulation of immune system process & 29 & 1391 & $1.59 \mathrm{E}-08$ \\
\hline GO:0043603 & cellular amide metabolic process & 21 & 732 & $3.29 \mathrm{E}-08$ \\
\hline GO:0051179 & localization & 57 & 5233 & $2.38 \mathrm{E}-07$ \\
\hline GO:0042987 & amyloid precursor protein catabolic process & 5 & 9 & $4.59 \mathrm{E}-07$ \\
\hline GO:0006952 & defense response & 25 & 1234 & $5.31 \mathrm{E}-07$ \\
\hline GO:0019538 & protein metabolic process & 49 & 4194 & $7.31 \mathrm{E}-07$ \\
\hline GO:0006518 & peptide metabolic process & 16 & 497 & $8.20 \mathrm{E}-07$ \\
\hline GO:0022610 & biological adhesion & 20 & 849 & $1.78 \mathrm{E}-06$ \\
\hline GO:0034205 & amyloid-beta formation & 4 & 5 & $4.74 \mathrm{E}-06$ \\
\hline GO:0007155 & cell adhesion & 19 & 843 & $7.34 \mathrm{E}-06$ \\
\hline GO:0071704 & organic substance metabolic process & 76 & 9135 & $7.89 \mathrm{E}-06$ \\
\hline GO:0006509 & membrane protein ectodomain proteolysis & 5 & 20 & $9.09 \mathrm{E}-06$ \\
\hline GO:0002526 & acute inflammatory response & 7 & 73 & $1.10 \mathrm{E}-05$ \\
\hline GO:0050776 & regulation of immune response & 19 & 873 & $1.14 \mathrm{E}-05$ \\
\hline GO:0006898 & receptor-mediated endocytosis & 10 & 209 & $1.27 \mathrm{E}-05$ \\
\hline GO:0008152 & metabolic process & 77 & 9569 & $2.55 \mathrm{E}-05$ \\
\hline GO:0031347 & regulation of defense response & 16 & 676 & $3.65 \mathrm{E}-05$ \\
\hline GO:0002003 & angiotensin maturation & 4 & 11 & 4.15E-05 \\
\hline GO:0043171 & peptide catabolic process & 5 & 31 & $5.24 \mathrm{E}-05$ \\
\hline GO:0005975 & carbohydrate metabolic process & 13 & 457 & $5.58 \mathrm{E}-05$ \\
\hline GO:0007586 & digestion & 7 & 104 & $8.52 \mathrm{E}-05$ \\
\hline
\end{tabular}




\begin{tabular}{|c|c|c|c|c|}
\hline GO:0050896 & response to stimulus & 66 & 7824 & 0.00012 \\
\hline GO:0098609 & cell-cell adhesion & 12 & 416 & 0.00012 \\
\hline GO:0044238 & primary metabolic process & 71 & 8808 & 0.00015 \\
\hline GO:0050778 & positive regulation of immune response & 14 & 589 & 0.00015 \\
\hline GO:0098742 & $\begin{array}{l}\text { cell-cell adhesion via plasma-membrane adhesion } \\
\text { molecules }\end{array}$ & 9 & 230 & 0.0002 \\
\hline GO:0002576 & platelet degranulation & 7 & 129 & 0.00029 \\
\hline GO:0002253 & activation of immune response & 11 & 393 & 0.00037 \\
\hline GO:0044245 & polysaccharide digestion & 3 & 6 & 0.00039 \\
\hline GO:0006954 & inflammatory response & 12 & 482 & 0.00044 \\
\hline GO:0046718 & viral entry into host cell & 6 & 92 & 0.00046 \\
\hline GO:0009056 & catabolic process & 25 & 1859 & 0.00052 \\
\hline GO:1901565 & organonitrogen compound catabolic process & 17 & 958 & 0.00052 \\
\hline GO:0002768 & $\begin{array}{l}\text { immune response-regulating cell surface receptor } \\
\text { signaling pathway }\end{array}$ & 9 & 266 & 0.00053 \\
\hline GO:0002684 & positive regulation of immune system process & 16 & 882 & 0.00067 \\
\hline GO:0006897 & endocytosis & 12 & 510 & 0.00067 \\
\hline GO:0051701 & interaction with host & 7 & 156 & 0.00077 \\
\hline GO:0098657 & import into cell & 13 & 609 & 0.00079 \\
\hline GO:0007156 & $\begin{array}{l}\text { homophilic cell adhesion via plasma membrane } \\
\text { adhesion molecules }\end{array}$ & 7 & 158 & 0.00081 \\
\hline GO:0002764 & immune response-regulating signaling pathway & 10 & 365 & 0.0009 \\
\hline GO:0050900 & leukocyte migration & 9 & 296 & 0.001 \\
\hline GO:0006026 & aminoglycan catabolic process & 5 & 67 & 0.0011 \\
\hline GO:0002429 & $\begin{array}{l}\text { immune response-activating cell surface receptor } \\
\text { signaling pathway }\end{array}$ & 8 & 234 & 0.0012 \\
\hline GO:1901575 & organic substance catabolic process & 22 & 1609 & 0.0012 \\
\hline GO:0044248 & cellular catabolic process & 22 & 1646 & 0.0016 \\
\hline GO:0080134 & regulation of response to stress & 19 & 1299 & 0.0017 \\
\hline GO:0043170 & macromolecule metabolic process & 60 & 7453 & 0.002 \\
\hline GO:0002757 & immune response-activating signal transduction & 9 & 332 & 0.0022 \\
\hline GO:0006953 & acute-phase response & 4 & 45 & 0.0031 \\
\hline GO:0090675 & intermicrovillar adhesion & 2 & 2 & 0.0037 \\
\hline GO:0045088 & regulation of innate immune response & 9 & 361 & 0.0038 \\
\hline GO:0006807 & nitrogen compound metabolic process & 64 & 8349 & 0.004 \\
\hline GO:0006950 & response to stress & 33 & 3267 & 0.004 \\
\hline GO:2000811 & negative regulation of anoikis & 3 & 18 & 0.004 \\
\hline GO:0007157 & $\begin{array}{l}\text { heterophilic cell-cell adhesion via plasma membrane cell } \\
\text { adhesion molecules }\end{array}$ & 4 & 54 & 0.0056 \\
\hline GO:0000023 & maltose metabolic process & 2 & 3 & 0.0058 \\
\hline GO:0016266 & O-glycan processing & 4 & 57 & 0.0066 \\
\hline GO:0046466 & membrane lipid catabolic process & 3 & 23 & 0.0071 \\
\hline GO:0010669 & epithelial structure maintenance & 3 & 24 & 0.0079 \\
\hline
\end{tabular}




\begin{tabular}{|c|c|c|c|c|}
\hline GO:1903596 & regulation of gap junction assembly & 2 & 4 & 0.0083 \\
\hline GO:0002223 & stimulatory C-type lectin receptor signaling pathway & 4 & 62 & 0.0085 \\
\hline GO:0006027 & glycosaminoglycan catabolic process & 4 & 62 & 0.0085 \\
\hline GO:1901136 & carbohydrate derivative catabolic process & 6 & 175 & 0.0085 \\
\hline GO:0006879 & cellular iron ion homeostasis & 4 & 66 & 0.0102 \\
\hline GO:0050727 & regulation of inflammatory response & 8 & 338 & 0.0104 \\
\hline GO:0006685 & sphingomyelin catabolic process & 2 & 5 & 0.0107 \\
\hline GO:0042445 & hormone metabolic process & 6 & 186 & 0.0107 \\
\hline GO:0045089 & positive regulation of innate immune response & 7 & 259 & 0.0107 \\
\hline GO:0072338 & cellular lactam metabolic process & 2 & 6 & 0.0138 \\
\hline GO:0044403 & symbiont process & 11 & 650 & 0.0151 \\
\hline GO:0031349 & positive regulation of defense response & 8 & 365 & 0.016 \\
\hline GO:0043687 & post-translational protein modification & 8 & 365 & 0.016 \\
\hline GO:0032532 & regulation of microvillus length & 2 & 7 & 0.017 \\
\hline GO:0006979 & response to oxidative stress & 8 & 373 & 0.0178 \\
\hline GO:0051186 & cofactor metabolic process & 9 & 467 & 0.0181 \\
\hline GO:0045785 & positive regulation of cell adhesion & 8 & 375 & 0.0182 \\
\hline GO:0050818 & regulation of coagulation & 4 & 81 & 0.0189 \\
\hline GO:0007229 & integrin-mediated signaling pathway & 4 & 84 & 0.0211 \\
\hline GO:0044281 & small molecule metabolic process & 20 & 1779 & 0.0219 \\
\hline GO:0002016 & regulation of blood volume by renin-angiotensin & 2 & 9 & 0.0243 \\
\hline GO:0002438 & acute inflammatory response to antigenic stimulus & 2 & 9 & 0.0243 \\
\hline GO:0008354 & germ cell migration & 2 & 9 & 0.0243 \\
\hline GO:0097205 & renal filtration & 2 & 9 & 0.0243 \\
\hline GO:0016477 & cell migration & 12 & 812 & 0.0246 \\
\hline GO:0050852 & T cell receptor signaling pathway & 4 & 93 & 0.0285 \\
\hline GO:0065008 & regulation of biological quality & 32 & 3559 & 0.0287 \\
\hline GO:0006022 & aminoglycan metabolic process & 5 & 160 & 0.0299 \\
\hline GO:0022409 & positive regulation of cell-cell adhesion & 6 & 238 & 0.0306 \\
\hline GO:0001878 & response to yeast & 2 & 11 & 0.0316 \\
\hline GO:0030155 & regulation of cell adhesion & 10 & 623 & 0.0316 \\
\hline GO:0032101 & regulation of response to external stimulus & 11 & 732 & 0.0316 \\
\hline GO:0097242 & amyloid-beta clearance & 2 & 11 & 0.0316 \\
\hline GO:0051181 & cofactor transport & 3 & 46 & 0.0328 \\
\hline GO:0002758 & innate immune response-activating signal transduction & 5 & 168 & 0.0341 \\
\hline GO:0019731 & antibacterial humoral response & 3 & 47 & 0.0341 \\
\hline GO:0042340 & keratan sulfate catabolic process & 2 & 12 & 0.0343 \\
\hline GO:1904469 & positive regulation of tumor necrosis factor secretion & 2 & 12 & 0.0343 \\
\hline GO:0042742 & defense response to bacterium & 6 & 250 & 0.0356 \\
\hline GO:0001822 & kidney development & 6 & 251 & 0.0361 \\
\hline GO:0043062 & extracellular structure organization & 7 & 339 & 0.0361 \\
\hline GO:0006959 & humoral immune response & 6 & 252 & 0.0363 \\
\hline GO:0002703 & regulation of leukocyte mediated immunity & 5 & 176 & 0.0379 \\
\hline
\end{tabular}




\begin{tabular}{|c|c|c|c|c|}
\hline GO:0006684 & sphingomyelin metabolic process & 2 & 13 & 0.0379 \\
\hline GO:0009251 & glucan catabolic process & 2 & 13 & 0.0379 \\
\hline GO:0044130 & negative regulation of growth of symbiont in host & 2 & 13 & 0.0379 \\
\hline GO:1901678 & iron coordination entity transport & 2 & 13 & 0.0379 \\
\hline GO:0008217 & regulation of blood pressure & 5 & 177 & 0.0385 \\
\hline GO:0031348 & negative regulation of defense response & 5 & 180 & 0.0411 \\
\hline GO:0044247 & cellular polysaccharide catabolic process & 2 & 14 & 0.0411 \\
\hline GO:0044273 & sulfur compound catabolic process & 3 & 53 & 0.0421 \\
\hline GO:0006575 & cellular modified amino acid metabolic process & 5 & 185 & 0.0447 \\
\hline GO:0002922 & positive regulation of humoral immune response & 2 & 15 & 0.0448 \\
\hline GO:0009311 & oligosaccharide metabolic process & 3 & 55 & 0.0449 \\
\hline GO:0051704 & multi-organism process & 22 & 2222 & 0.0449 \\
\hline GO:0045087 & innate immune response & 10 & 676 & 0.046 \\
\hline GO:0022407 & regulation of cell-cell adhesion & 7 & 366 & 0.0476 \\
\hline GO:0016032 & viral process & 9 & 571 & 0.0478 \\
\hline GO:0033013 & tetrapyrrole metabolic process & 3 & 57 & 0.048 \\
\hline GO:0050728 & negative regulation of inflammatory response & 4 & 117 & 0.048 \\
\hline GO:0051883 & $\begin{array}{l}\text { killing of cells in other organism involved in symbiotic } \\
\text { interaction }\end{array}$ & 2 & 16 & 0.048 \\
\hline GO:1903037 & regulation of leukocyte cell-cell adhesion & 6 & 278 & 0.0488 \\
\hline GO:0008015 & blood circulation & 7 & 373 & 0.0498 \\
\hline
\end{tabular}




\section{Supplementary note}

\section{Application on analyzing an artificial microbiota community consisted with pure cultures}

To evaluate the performance of open search in metaproteomics studies, we analyzed a microbiome dataset which was constructed by assembling 32 species/ and strains of Archaea, Bacteria, Eukaryotes and Bacteriophages $6.1,048,759$ PSMs were identified from 24 raw files with FDR about $0.1 \%$. Totally 70,108 unique peptide sequences and 16,444 proteins were found with FDR at peptide and protein levels $0.24 \%$ and $1 \%$, respectively (Supplementary Data 6$) .31 .4 \%(22,043 / 70,108)$ of the unique peptides contained at least one modified forms. The ratio reached $80 \%(9,061 / 11,328)$ at the protein level, which meant four-fifths of proteins contained at least one modification. This result clearly illustrated that PTMs widely occured on proteins of microbes.

For this dataset, the mock communities were mixed with three different ways, i.e., equal cell number mixture, equal protein amount mixture and uneven mixture. For each type the relative abundance of individual bacterial members were known. Therefore we used this dataset to benchmark the quantitative accuracy of our method. Firstly, we used all the peptides, only modified peptides and only unmodified peptides, respectively, to calculate the relative abundance of each species from each mixture types (Supplementary Fig. 4a). The distribution of relative abundance, determined in different ways, was consistent which also suggested the equal confidence of the modified and unmodified peptide identifications.

The species-level quantification result was showed in Supplementary Fig. 4b. As expected, for most of the species very good representations of the relative abundances were observed. For the equal cell number mixture and equal protein amount mixture accurate quantitative results were obtained for most of the species. Bacteriophages were observed with apparent deviations from the theory values because their abundance were ten times lower than other species. In the uneven mixture, the deviation was larger, may be because differences between individual species became larger and the theoretical abundances for some species were low. 
Taxonomy analsyis and functional annotation of the glycopeptides identified in human gut microbiome dataset

Glycosylation plays a critical role in the regulation of protein functions. The alterations of glycosylation could affect the immune system of mammals ${ }^{9}$. The relationship between abnormal glycosylation and the pathogenesis of diabetes has also been reported ${ }^{10}$. Functional enrichment analysis of HexNAc modified proteins was performed (Supplementary Table 5). Neutrophil related immune response was the most significantly enriched biological processes (Supplementary Fig. 10). Among the enriched Gene Ontology $(\mathrm{GO})$ terms, nine of them were changed ( $p<0.05$ by two-sample, two-tailed t-test) (Supplementary Fig. 11). Five of them (transport, response to stress, inflammatory response, response to stimulus and localization) were also downregulated in NO samples which were consistent with the general trend. But four catabolic processes (catabolic process, cellular catabolic process, organonitrogen compound catabolic process and organic substance catabolic process) related functions were upregulated.

Besides high abundant human protein glycosylation, we also identified three types of glycosylation from microbial proteins. For hexose, 21 glycopeptides were identified, only one peptide was from Bacteroidetes and 16 peptides were from Firmicutes (Supplementary Fig. 12, Supplementary Table 6). In this dataset, $86.7 \%(39 / 45)$ of the hexose modified PSMs were from Clostridiales. From the functional annotation, we found that the most frequently observed function related to hexose was ABC-type glycerol-3-phosphate transport system, periplasmic component (Supplementary Fig. 13). For HexNAc2, one peptide EAATTAAAAAATTDVADKK was identified from eight CO and seven NO samples, respectively, which was the most widely identified glycopeptide from bacteria in Human_gut (Supplementary Fig. 14, Supplementary Table 6). The lowest common ancestor (LCA) of this peptide was Clostridia (order level). The corresponding protein was ABC-type sugar transport system, periplasmic component, contains $\mathrm{N}$-terminal xre family $\mathrm{HTH}$ domain, which was also an ATP-binding cassette $(A B C)$ transporter. It could be seen that the $A B C$ transporter families were the most frequently identified glycoproteins from bacteria in Human_gut. We also identified bacteria specific monosaccharide Bacillosamine from 48 glycopeptides. Bacillosamine was described as an "Asn-linked glycan from Gram-negative Bacterium" in Unimod. However, we noticed that only $45.8 \%(22 / 48)$ glycopeptides contained Asn, which suggested the existence of other types such as O-linked 
glycopeptides in these samples. Bacillosamine was involved in various functions in this dataset (Supplementary Table 6). We identified the LCA for 21 glycopeptides (Supplementary Fig. 15). Three peptides determined in superkingdom level as bacteria were from the protein Elongation factor Tu (EF-Tu), which was a highly conserved proteins in prokaryotes. EF-Tu was a type of GTPase, which was also an important antibiotic target ${ }^{11}$. For the remainder of the glycopeptides, seven were from Bacteroidetes and eight were from Firmicutes. The main COG categories were carbohydrate transport and metabolism (G) and energy production and conversion (C). The characterization of bacteria glycosylation will greatly improve our understanding of gut microbiome-host interactions.

1. Chick, J.M. et al. A mass-tolerant database search identifies a large proportion of unassigned spectra in shotgun proteomics as modified peptides. Nat. Biotechnol. 33, 743-749 (2015).

2. Potel, C.M., Lin, M.H., Heck, A.J.R. \& Lemeer, S. Defeating major contaminants in Fe(3+)-IMAC phosphopeptide enrichment. Mol Cell Proteomics (2018).

3. Humphrey, S.J., Azimifar, S.B. \& Mann, M. High-throughput phosphoproteomics reveals in vivo insulin signaling dynamics. Nat. Biotechnol. 33, 990-U142 (2015).

4. Espadas, G., Borras, E., Chiva, C. \& Sabido, E. Evaluation of different peptide fragmentation types and mass analyzers in data-dependent methods using an Orbitrap Fusion Lumos Tribrid mass spectrometer. Proteomics 17 (2017).

5. Humphrey, S.J., Karayel, O., James, D.E. \& Mann, M. High-throughput and high-sensitivity phosphoproteomics with the EasyPhos platform. Nat. Protoc. 13 (2018).

6. Kleiner, M. et al. Assessing species biomass contributions in microbial communities via metaproteomics. Nat Commun 8 (2017).

7. Zhang, X. et al. MetaPro-IQ: a universal metaproteomic approach to studying human and mouse gut microbiota. Microbiome 4 (2016).

8. Gavin, P.G. et al. Intestinal Metaproteomics Reveals Host-Microbiota Interactions in Subjects at Risk for Type 1 Diabetes. Diabetes Care 41, 2178-2186 (2018).

9. Marth, J.D. \& Grewal, P.K. Mammalian glycosylation in immunity. Nat Rev Immuno/ 8, 874-887 (2008).

10. Bermingham, M.L. et al. N-Glycan Profile and Kidney Disease in Type 1 Diabetes. Diabetes Care 41, 7987 (2018).

11. Parmeggiani, A. \& Nissen, P. Elongation factor Tu-targeted antibiotics: Four different structures, two mechanisms of action. Febs Lett 580, 4576-4581 (2006). 